\title{
Impacts of silicon and silicon nanoparticles on leaf ultrastructure and TaPIP1 and TaNIP2 gene expressions in heat stressed wheat seedlings
}

\author{
A.A. YOUNIS*, H. KHATTAB, and M.M. EMAM \\ Botany Department, Faculty of Science, Ain Shams University, Cairo 11566, Egypt
}

\begin{abstract}
Heat stress is one of the most crucial factors affecting crop growth and productivity worldwide. So, searching for a potent eco-friendly heat stress alleviator is the main issue nowadays. The current study was conducted to assess the ameliorative effects of $1.5 \mathrm{mM}$ potassium silicate $\left(\mathrm{K}_{2} \mathrm{SiO}_{3}\right.$, further only $\left.\mathrm{Si}\right)$ or $1.66 \mathrm{mM}$ silicon dioxide nanoparticles (SiNPs) on wheat (Triticum aestivum L.) seedlings exposed to heat stress $\left(45^{\circ} \mathrm{C}, 4 \mathrm{~h}\right)$. The observations show that Si or SiNPs treatments significantly restored the heat stress-provoked ultrastructural distortions of cellular organelles, particularly chloroplasts and the nucleus. Further, both Si and SiNPs enhanced the photosynthetic capacity as revealed by increments in the photochemical efficiency of photosystem II and the performance index as well as the content of photosynthetic pigments. A reduction in malondialdehyde accumulation in Si and SiNPs treated plants was positively related to their membrane stability index. The reverse transcription PCR analysis showed that Si treatment but not SiNP treatment stimulated the overexpressions of both Triticum aestivum plasma membrane intrinsic protein (TaPIP1) and Triticum aestivum nodulin 26-like intrinsic protein (TaNIP2) aquaporin genes parallelly with an improvement in the relative water content. This investigation reveals that $\mathrm{Si}$ was more effective than SiNPs in restoring the heat stress injuries. To the best of our knowledge, this is the first investigation exploring the effects of Si and SiNPs in improving thermotolerance of wheat seedlings.
\end{abstract}

Additional key words: aquaporins, chlorophyll content, chlorophyll fluorescence, membrane stability, photosystem II, Triticum aestivum.

\section{Introduction}

Heat stress is one of the main challenges induced abiotic stresses. Plants exposed to high temperatures experience metabolic changes which may lead to cell death (Ihsan et al. 2019). Heat stress provokes ultrastructural deformations of cellular organelles, particularly chloroplasts and mitochondria (Liu et al. 2013). It has been reported that heat stress induces damage to the chloroplasts including, excessive swelling of the outer chloroplast membrane, distortion of the stroma and intergranal lamellar system, disorganization of thylakoids concomitant with reduction in grana stacking thickness, decline in starch granules size, and increments in the numbers of plastoglobuli (Liu et al. 2013, Wang et al. 2018). The disorganization of thylakoid membranes concomitant with the loss of the thylakoid membrane integrity was reported as an important marker in many heat-sensitive plants (Dankov et al. 2015, Li et al. 2016). Similarly, the photosynthetic performance index $\left(\mathrm{PI}_{\mathrm{abs}}\right)$, photochemical efficiency of photosystem II $\left(\mathrm{F}_{\mathrm{V}} / \mathrm{F}_{\mathrm{M}}\right)$, chlorophyll biosynthesis, and the net photosynthetic rate $\left(\mathrm{P}_{\mathrm{N}}\right)$ are thermally labile parameters that reflect the efficiency of the photosynthetic system (Djanaguiraman et al. 2018, Wang et al. 2019b). It was reported that, the photochemical efficiency was reduced by heat stress resulting in the production of reactive oxygen species (ROS) which in turn trigger lipid peroxidation in wheat plants (Wang et al. 2014).

Water status is the main physiological parameter of plants influenced by heat stress (Christou et al. 2014). Generally, heat stimulates water loss via enhancement of transpiration rate and thereby impairing plant water balance (Fahad et al. 2017). Plants tolerate heat stress by evolving different biochemical and molecular strategies, including regulation of water/osmotic homeostasis, ion balance, as well as controlling water transport via aquaporins (AQPs; Kapilan et al. 2018, Khan et al. 2019). The AQPs are the main membrane transporters of water (Yaneff et al. 2016).

Submitted 9 August 2019, last revision 2 February 2020, accepted 20 February 2020.

Abbreviations: AQP - aquaporin; Car - carotenoids; Chl - chlorophyll; DPPH - 2,2-diphenyl-1-picrylhydrazyl; $\mathrm{F}_{\mathrm{V}} / \mathrm{F}_{\mathrm{M}}$ - variable to maximum chlorophyll fluorescence ratio (photochemical efficiency of photosystem II); MDA - malondialdehyde; MSI - membrane stability index; NIP - nodulin 26-like intrinsic protein; $\mathrm{PI}_{\text {abs }}$ - performance index; PIP - plasma membrane intrinsic protein; PS II photosystem II; RWC - relative water content; SiNP - silicon dioxide nanoparticle; TEM - transmission electron microscope/microscopy. Acknowledgments: Authors acknowledge the partial support of the community service and environmental development affairs sector of Ain Shams University.

*Corresponding author; e-mail: abeeryounis@sci.asu.rdu.eg 
It was reported earlier that, the transfer of water via AQPs is sensitive to temperature (Ionenko et al. 2010). Plant AQPs are also involved in the transport of small molecules such as $\mathrm{Si}, \mathrm{B}, \mathrm{O}_{2}, \mathrm{CO}_{2}, \mathrm{NH}_{4}$, and $\mathrm{H}_{2} \mathrm{O}_{2}$ (Maurel et al. 2015, Zwiazek et al. 2017). The plant AQPs family is divided into five subfamilies according to amino acid sequence homology and protein subcellular localization (Hussain et al. 2011): plasma membrane intrinsic proteins (PIPs), tonoplast membrane intrinsic proteins (TIPs), nodulin 26like intrinsic proteins (NIPs), small basic intrinsic proteins, and uncharacterized-intrinsic proteins (XIPs) (Gupta and Sankararamakrishnan 2009, Park et al. 2010). Changes in aquaporin genes expression in response to heat stress have been reported in various plant species including strawberry and spinach (Chen and Arora 2014, Christou et al. 2014).

Wheat (Triticum aestivum) is one of the most important food crops worldwide (Curtis and Halford 2014). However, the growth and productivity of wheat is affected by environmental stresses such as drought, salinity, and extreme temperature. Wheat as a temperate crop has an optimum growth temperature at $23-25^{\circ} \mathrm{C}$ and is generally injured at temperatures above $25{ }^{\circ} \mathrm{C}$ (Blum 1986). Wheat is grown in about $30 \%$ of the world cereal area and about $50 \%$ of such area experiences high temperature stress (Cossani and Reynolds 2012). Nowadays, it is crucial to enhance wheat thermotolerance to meet the global food demands. So, searching for potent and ecofriendly heat alleviators play an important role in enhancing wheat productivity under stressful condition.

Different forms of silicon could be used as environmental stress alleviators (Asgari et al. 2018). Silicon has numerous beneficial effects in enhancing plant growth and development, particularly under stressful conditions (Alzahrani et al. 2018, Asgari et al. 2018). It has been reported that silicon can be deposited in the walls of the epidermal and vascular tissues of stems and leaves in most plant species, especially monocots, thereby affecting the physiological properties of plants (Gong and Chen 2012, Rios et al. 2017). In addition, application of silicon was capable to enhance the plant water uptake and transport (Yavaş and Aydın 2017), the antioxidant activities (Ma et al. 2016), the photosynthetic performance (Wang et al. 2019b), and the expression of antioxidant genes (Abdel Latef and Tran 2016). Silicon dioxide nanoparticles (SiNPs) are currently considered a novel silicon source that can be used to increase plant tolerance to stress. Several studies have explored the effects of SiNPs on salt-stressed and metal-stressed plants (Alsaeedia et al. 2018, Hussain et al. 2019). However, the impact of SiNPs on mitigation of heat stress has not been investigated yet. Nanoparticles influence plant metabolism via utilization as micronutrients (Liu and Lal 2015), regulation of gene expressions (Nair and Chung 2014), or affection of different antioxidants (Hossain et al. 2015). However, no clear comparative studies concerning the mechanisms of $\mathrm{K}_{2} \mathrm{SiO}_{3}$ and SiNPs alleviation of heat stress were done. Thus, the present study was conducted to compare their protective roles against heat stress by improving water status and the photosynthesis capacity, and by maintaining ultrastructure of wheat seedling leaves.

\section{Materials and methods}

Plants and growth conditions: Wheat (Triticum aestivum L.) cv. Gemeza11 grains were obtained from the Agricultural Research Centre, Giza, Egypt, and kept in the dark at $4{ }^{\circ} \mathrm{C}$ before use. Potassium silicate and SiNPs were obtained from Sigma-Aldrich (St. Louis, USA). The SiNPs characteristics were: $99.5 \%$ purity and $20-30 \mathrm{~nm}$ particle size. The SiNPs was suspended in water by sonicating the silicon particles at $10 \mathrm{MHz}$ for $\sim 40$ min resulting in a partially homogeneous solution. The grains were surface sterilized by immersion in $1 \%$ $(\mathrm{m} / \mathrm{v})$ sodium hypochlorite solution for $5 \mathrm{~min}$. The grains were then rinsed thoroughly with running distilled water. The sterilized wheat grains were divided into three sets; the first set was soaked in water (control), the second and third sets were soaked in SiNPs $(1.66 \mathrm{mM})$ or $\mathrm{K}_{2} \mathrm{SiO}_{3}$ $(1.5 \mathrm{mM})$, respectively, for $8 \mathrm{~h}$ at room temperature $\left(25 \pm 2{ }^{\circ} \mathrm{C}\right)$. The soaked grains were immediately sown in plastic pots $(20 \times 20 \mathrm{~cm})$ containing $2 \mathrm{~kg}$ of soil composed of sieved air-dried clay and washed sand $(1: 1$, $\mathrm{m} / \mathrm{m})$. The experiment was conducted using a completely randomized design at Faculty of Science, Ain Shams University, Egypt using two controlled growth chambers (model V3-DM, Vision Scientific Company, Daejeon$\mathrm{Si}$, Korea) which were maintained at $24 / 18^{\circ} \mathrm{C}$ day/night temperatures, a $70 \%$ relative humidity, a photosynthetic photon flux density (PPFD) of $250 \mu \mathrm{mol} \mathrm{m} \mathrm{m}^{-2} \mathrm{~s}^{-1}$, and a 16-h photoperiod; a water holding capacity of the soil was maintained at $70 \%$. Water holding capacity (WHC) of the soil was determined using a modified method of Bajwa et al. (2017). To restore the appropriate WHC, each pot was weighed using an electronic digital balance every day and appropriate quantity of water was added to the soil. After $14 \mathrm{~d}$, the untreated seedlings (control) were then split into two further subsets. The first subset was kept in the optimal temperature chamber to serve as a control. The second subset and the SiNPs- or $\mathrm{K}_{2} \mathrm{SiO}_{3}$ (further only $\mathrm{Si}$ )treated seedlings were kept in the second chamber and exposed to high temperature of $45^{\circ} \mathrm{C}$ for $4 \mathrm{~h}$. Then, the fully expanded leaves from the second internodes of twoweeks-old were collected, frozen in liquid nitrogen and then stored at $-80^{\circ} \mathrm{C}$ for biochemical analyses.

Leaf ultrastructure: Samples $\left(1 \mathrm{~cm}^{2}\right)$ from the middle of the second flag leaves were collected, then sliced and fixed immediately in $4 \%(\mathrm{~m} / \mathrm{v})$ glutaraldehyde in $100 \mathrm{mM}$ sodium cacodylate buffer, at $\mathrm{pH} 7.2$ overnight. Following glutaraldehyde fixation, samples were post-fixed in $2 \%(\mathrm{~m} / \mathrm{v})$ osmium tetroxide in the same cacodylate buffer, stained in $1 \%(\mathrm{~m} / \mathrm{v})$ aqueous uranyl acetate for $8 \mathrm{~h}$, dehydrated in acetone, and embedded in Spurr'resin (Spurr 1969). The samples (ultrathin sections, $300 \mathrm{~nm}$ ) were then examined under transmission electron microscope (TEM; JEM 1011, JEOL, Tokyo, Japan) at $80 \mathrm{kV}$, and photographed for image analysis with an $A M T$ digital image capture system.

Pigment content and chlorophyll fluorescence: The photosynthetic pigments chlorophyll (Chl) $a$, Chl $b$, and 
carotenoids (Car) were extracted in $80 \%$ (v/v) acetone and measured spectrophotometrically (Spectronic 601, Milton Roy Company, Rochester, NY, USA) according to Metzner et al. (1965).

Leaf Chl $a$ fluorescence was measured using a pulse amplitude modulation portable fluorometer (Handy PEA, Hansatech, Norfolk, UK). The leaves were dark adapted in a leaf clip for $30 \mathrm{~min}$. For all treatments, 30 measurements (three replicates of 10 leaves from different plants) were recorded. The data obtained were used to calculate the maximum efficiency of PS II $\left(\mathrm{F}_{\mathrm{V}} / \mathrm{F}_{\mathrm{M}}\right)$ and performance index on absorption basis ( $\mathrm{PI}_{\mathrm{abs}}$ ) (Strasser et al. 2004) according to the equations reviewed by (Stirbet and Govindjee 2011)

Lipid peroxidation was evaluated by measuring the production of malondialdehyde (MDA) by the thiobarbituric acid (TBA)-based colorimetric method as described by Heath and Packer (1968).

Membrane stability index (MSI) was determined according to Sairam et al. (2002). Leaf samples (200 mg) were immersed in $10 \mathrm{~cm}^{3}$ of of deionized water and divided into 2 sets. One set was kept at $40{ }^{\circ} \mathrm{C}$ for $30 \mathrm{~min}$ and its conductivity recorded $(\mathrm{C} 1)$ using a conductivity meter (HI 8733, Hanna Instruments, Woonsocket, RI, USA). The second set was kept in a boiling water bath $\left(100{ }^{\circ} \mathrm{C}\right)$ for $15 \mathrm{~min}$ and its conductivity was also recorded (C2). The MSI was calculated as: $\mathrm{MSI}=[1-(\mathrm{C} 1 / \mathrm{C} 2)] \times 100$.

Relative water content (RWC) was measured according to the method described by Pieczynski et al. (2013). Leaf discs were taken from the fully expanded and uniform leaves. The fresh mass (FM) was recorded, and then samples were placed in a Petri dish with distilled water for $4 \mathrm{~h}$. The water saturated mass (WSM) was then recorded, and the leaf samples were placed in an oven at $80{ }^{\circ} \mathrm{C}$ for $48 \mathrm{~h}$, to determine the dry mass (DM). Leaf RWC was calculated as: $\mathrm{RWC}[\%]=[(\mathrm{FM}-\mathrm{DM}) /(\mathrm{WSM}-\mathrm{DM}] \times$ 100 .

Activity of 2,2-diphenyl-1-picrylhydrazyl (DPPH) radical scavenging was determined using the method described by Hatano et al. (1988). A volume of $4 \mathrm{~cm}^{3}$ of each sample was added to $1 \mathrm{~cm}^{3}$ of methanolic solution of 2,2diphenyl-1-picrylhydrazyl (DPPH) (0.2 mM). The mixture was kept at room temperature for $30 \mathrm{~min}$ before measuring the changes in absorbance at $517 \mathrm{~nm}$. The DPPH radical scavenging activity was calculated as $\left[\left(\mathrm{A}_{0}-\mathrm{A}_{1}\right) / \mathrm{A}_{0}\right] \times 100$, where $A_{0}$ is the absorbance of the DPPH solution and $A_{1}$ is the absorbance of the sample.

Gene expression analysis: Total RNA was extracted from wheat leaves of all treatments using the RNeasy Plant Mini kit (Qiagen, Amsterdam, The Netherlands). Total RNA $(1 \mu \mathrm{g})$ from each sample was converted into cDNA by reverse transcription using the RNA PCR kit (TaKaRa, Tokyo, Japan) according to the manufacturer's instructions. The RT-qPCR was conducted on an ABI 7500 system (Applied Biosystems, New York, NY, USA) using a TransStart ${ }^{\mathrm{TM}}$ Green qRT-PCR Super Mix kit (TransGen, Beijing, China). A TaActin rRNA (GenBank accession No. AB181991) was used as a reference gene to normalize the relative transcription and to minimize different copy numbers of cDNA templates. The control sample was conferred a value of 1 . All data were calculated and analyzed from three independent samples based on the $2^{-\Delta \Delta \mathrm{Ct}}$ method (Livak and Schmittgen 2001). The primers of the Triticum aestivum plasma membrane intrinsic protein TaPIP1 and Triticum aestivum nodulin 26-like intrinsic protein TaNIP2 genes (Table 1 Suppl.) used in quantitative reverse transcription PCR excluded the highly conserved protein domain and had a high efficiency and specificity.

Statistical analysis: Analysis of variance ( $A N O V A)$ for the current data were performed using SPSS v. 20.0 (SPSS, Chicago, USA) software. Statistical significances of the means were compared by the Duncan's test at $P \leq 0.05$.

\section{Results}

The leaf ultrastructure of normal wheat cells was found to have a densely packed nucleus with an intact envelope (Fig. 1A). The exposure of wheat seedlings to heat stress induced ultrastructural distortion of the nucleus (Fig. 1B). Chromatin was unequally dispersed and agglutinated with heterochromatin. In addition, there was no distinct boundary between the nucleolus and chromatin (Fig. 1B). Meanwhile, the treatment with either $\mathrm{Si}$ or SiNPs maintained to some extent the integrity of the nuclear envelope and markedly dispersed chromatin appearance (Fig. 1C,D).

The results also showed that the chloroplasts have an ellipsoid shape with an intact membrane, concomitant with clearly arranged thylakoid segments in control unstressed leaves (Fig. 2A). However, heat stress imposed several changes in chloroplast ultrastructure including their swelling, expanding of matrix zone, and loosening of lamella structure (Fig. 2B). In addition, the number and size of plastoglobuli markedly increased in heatstressed leaves compared with unstressed ones (Fig. 2B). As shown in Fig. 2C,D, Si or SiNPs treatments alleviated the heat induced deleterious effects as reflected by less occurence of irregular grana lamellae and less damaged chloroplast envelopes. Additionally, the heat-stressed leaves exhibited reductions in $\mathrm{Chl} a$, Chl $b$, and total $\mathrm{Chl}$ content as well as in $\mathrm{Chl} / \mathrm{Car}$ ratio. However, the Car content markedly increased in the stressed wheat leaves (Table 1). Furthermore, heat stress induced apparent reduction in $\mathrm{PI}_{\mathrm{abs}}$ and $\mathrm{F}_{\mathrm{V}} / \mathrm{F}_{\mathrm{M}}$ values (Fig. $3 A, B$ ). Notably, $\mathrm{Si}$ or SiNPs treatments improved these parameters. The greater alleviation of negative effects of heat stress on Chl content, $\mathrm{PI}_{\mathrm{abs}}$, and $\mathrm{F}_{\mathrm{V}} / \mathrm{F}_{\mathrm{M}}$ was in Si-treated leaves compared with SiNPs ones (Table 1, Fig. $3 A, B$ )

Membrane ultrastructure of control wheat cells appeared normal in shape with large intercellular junctions (Fig. 4A). On the other hand, observations revealed damaged in plasma membranes and cell walls of heatstressed wheat leaves; the plasma membranes seemed to 
YOUNIS et al.
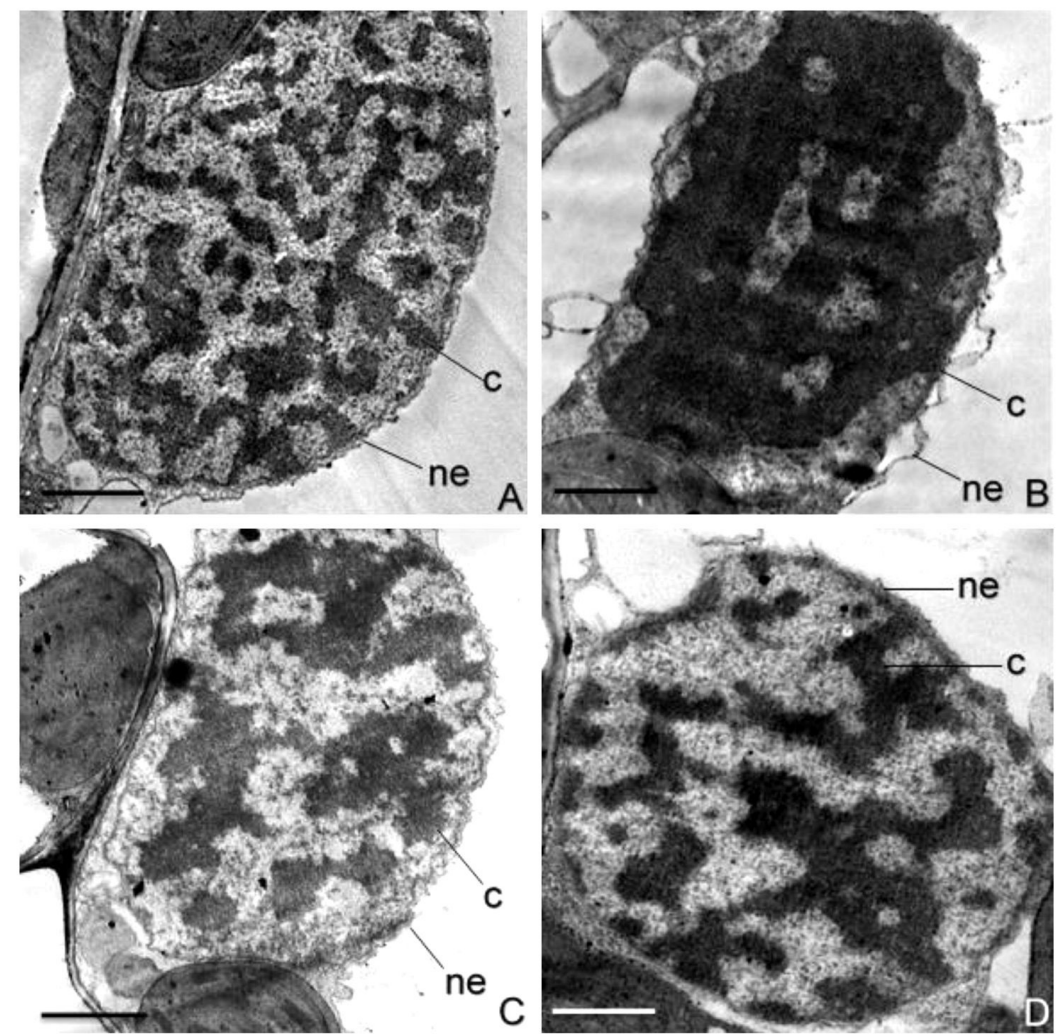

Fig. 1. Effect of potassium silicate ( $\mathrm{Si}$ ) or silicon dioxide nanoparticles (SiNPs) on nucleus ultrastructure of mesophyll cells from wheat leaves. $A$ - control, normal temperature, $B$ - heat stress $\left(45^{\circ} \mathrm{C}\right.$ for $\left.4 \mathrm{~h}\right), C$ - Si pretreatment + heat stress, $D$ - SiNP pretreatment + heat stress; ne - nuclear envelope, c - chromatin; bars are $500 \mathrm{~nm}$.
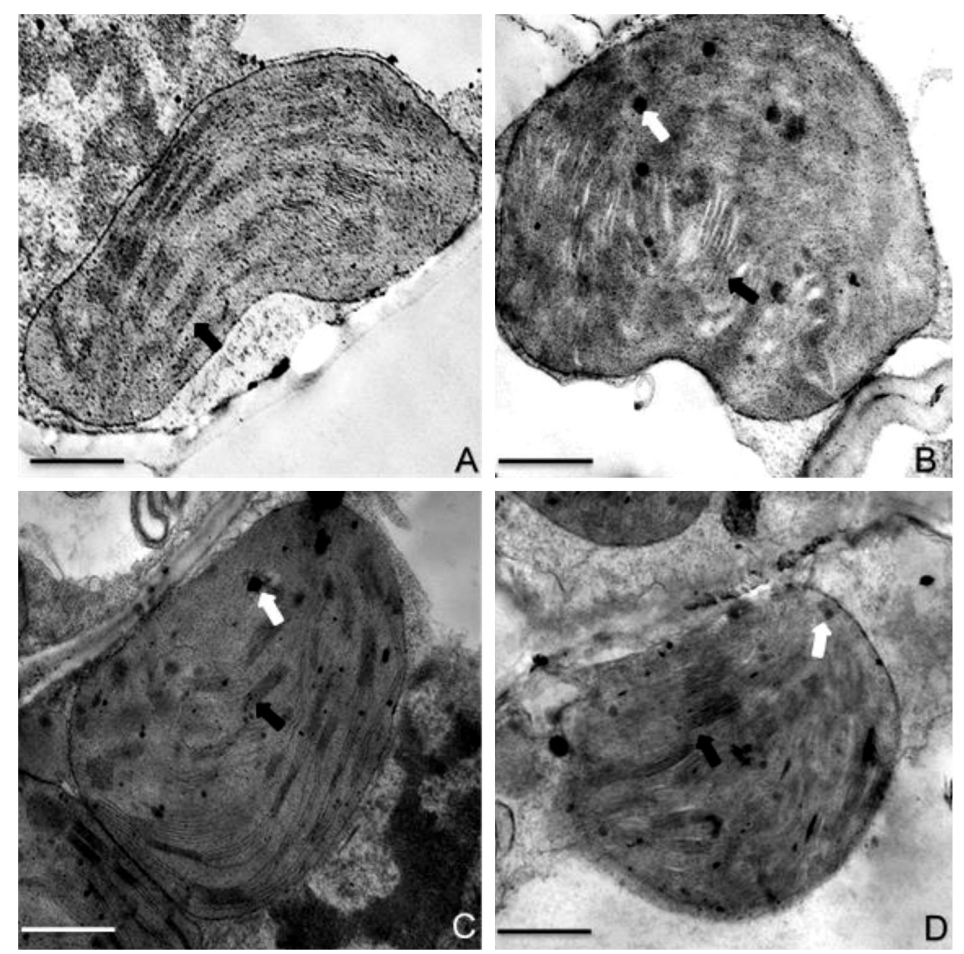

Fig. 2. Effect of potassium silicate (Si) or silicon dioxide nanoparticles (SiNPs) on chloroplast ultrastructure of mesophyll cells from wheat leaves. $A$ - control, normal temperature, $B$ - heat stress $\left(45^{\circ} \mathrm{C}\right.$ for $\left.4 \mathrm{~h}\right), C$ - Si pretreatment + heat stress, $D$ - SiNP pretreatment + heat stress; black arrows point to grana lamellae, white arrows point to plastoglobuli; bars are $500 \mathrm{~nm}$. 


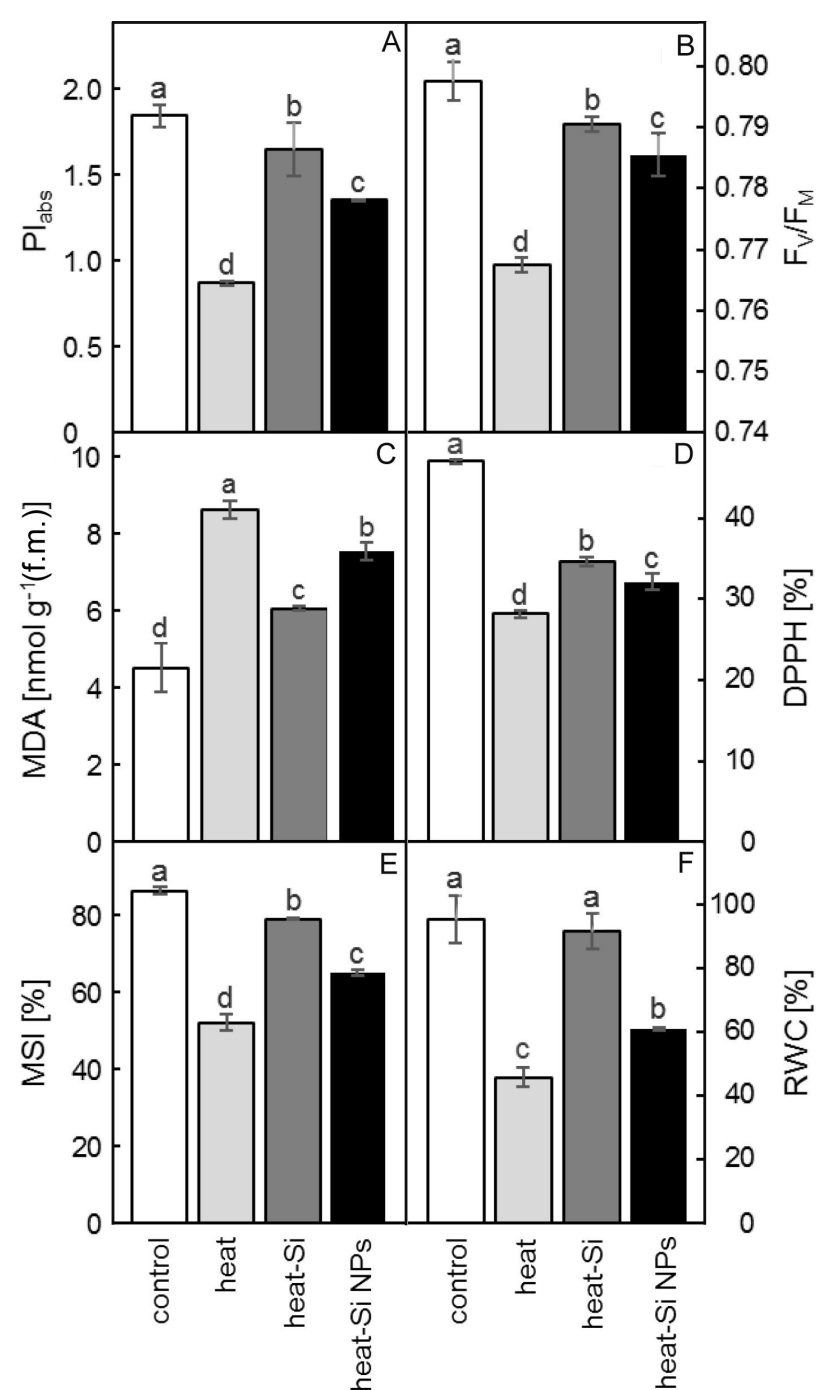

Fig. 3. Effect of heat stress and potassium silicate $(\mathrm{Si})$ or silicon dioxide nanoparticle (SiNP) pretreatment on: $A$ - performance index $\left(\mathrm{PI}_{\mathrm{abs}}\right), B$ - maximum efficiency of photosystem II $\left(\mathrm{F}_{\mathrm{v}} / \mathrm{F}_{\mathrm{M}}\right)$, $C$ - malondialdehyde (MDA) content, $D$ - 2,2-diphenyl-1-picrylhydrazyl (DPPH) scavenging activity, $E$ - membrane stability index (MSI), and $F$ - relative water content (RWC) of wheat seedlings. Means \pm SEs, $n=3$, different letters indicate significant differences at $P \leq 0.05$.

be detached from the cell wall, and the intercellular spaces of cells appeared more compacted (Fig. 4B). The plasma membrane distortion was associated with a significant increment in the MDA content (about 2-fold) of heat stressed leaves (Fig. 3C). However, the mesophyll cells of Si- or SiNPs-treated leaves maintained an integrated structure and relatively thick cell wall (Fig. 4C,D). In addition, both $\mathrm{Si}$ and $\mathrm{SiNPs}$ treatments alleviated extensive membrane damage, as shown by increasing MSI and nullifying membrane lipid peroxidation as observed by the reduction of MDA content (Fig. $3 C, E$ ). The DPPH scavenging activity was significantly increased in $\mathrm{Si}$ and SiNPs treated leaves as compared to that in non-treated heat-stressed leaves (Fig. 3D). Such effects were more pronounced in Si-treated leaves. The present results also showed that the RWC significantly decreased in heat stressed leaves. The Si treatment significantly increased RWC by about two folds compared to the untreated stressed leaves (Fig. $3 F$ ). In addition, the RT-PCR analysis showed that the TaPIP1 and TaNIP2 expressions were downregulated in heat-stressed leaves compared to the unstressed control ones (Fig. 5). However, both genes were significantly upregulated in Si-stressed leaves (Fig. 5). On the other hand, the expressions of the both genes were relatively unchanged in SiNPs- treated leaves as compared with heat-stressed ones (Fig. 5).

\section{Discussion}

The environmental stresses, particularly heat stress, induced metabolic disruptions which are recognized by the ultrastructure distortions of cell organelles. The electron microscopy analysis showed that imposition of heat stress caused the damages of chloroplasts (swollen thylakoids, increased abundance of plastoglobuli) and nucleus (condensation of chromatin) in wheat mesophyll cells (Figs. 1, 2, and 4). The observed changes of nuclear chromatin organization might be attributed to the modification in the chromatin configurations (LangMladek et al. 2010). Similar disruptions in chromatin under heat stress have been reported by Santos et al. (2011) in rice and by Pecinka et al. (2010) in Arabidopsis. However, the pretreatment of wheat with Si or SiNPs minimized the heat stress-induced adverse ultrastructural alterations as revealed by maintaining the integrity of nuclear envelope and the normal dispersion of chromatin (Fig. $1 C, D$ ). In fact, it is evident that silicon possesses multifaceted role in the regulation of genes involved in stress resistance

Table 1. Effect of silicon or silicon dioxide nanoparticles (SiNPs) on content of chlorophylls (Chl) and carotenoids (Car) [ $\mu \mathrm{g} \mathrm{g} \mathrm{g}^{-1}(\mathrm{~d} . \mathrm{m}$.$) ]$ in wheat leaves exposed to heat stress alone or after pretreatment with $1.5 \mathrm{mM} \mathrm{K}_{2} \mathrm{SiO}_{3}$; ( $\mathrm{Si}$ ) or $1.66 \mathrm{mM} \mathrm{SiNPs}$. Means $\pm \mathrm{SEs}, n=3$, different letters indicate significant differences at $P \leq 0.05$.

\begin{tabular}{llllrl}
\hline Treatment & Chl $a$ & Chl $b$ & Chl $a+b$ & Car & Chl a+b/Car \\
\hline Control & $546.672 \pm 6.7^{\mathrm{a}}$ & $338.573 \pm 5.9^{\mathrm{a}}$ & $885.248 \pm 0.8^{\mathrm{a}}$ & $69.461 \pm 2.0^{\mathrm{d}}$ & $4.44 \pm 6.7^{\mathrm{a}}$ \\
Heat & $376.964 \pm 0.4^{\mathrm{d}}$ & $218.078 \pm 3.2^{\mathrm{d}}$ & $595.042 \pm 3.6^{\mathrm{d}}$ & $106.817 \pm 2.6^{\mathrm{a}}$ & $1.96 \pm 0.5^{\mathrm{d}}$ \\
Heat $+\mathrm{Si}$ & $497.924 \pm 0.9^{\mathrm{b}}$ & $305.407 \pm 5.2^{\mathrm{b}}$ & $803.331 \pm 6.2^{\mathrm{b}}$ & $65.975 \pm 1.2^{\mathrm{c}}$ & $4.27 \pm 1.4^{\mathrm{b}}$ \\
Heat + SiNPs & $413.084 \pm 0.6^{\mathrm{c}}$ & $241.087 \pm 1.4^{\mathrm{c}}$ & $654.171 \pm 0.7^{\mathrm{c}}$ & $89.397 \pm 0.4^{\mathrm{b}}$ & $2.55 \pm 0.6^{\mathrm{c}}$ \\
\hline
\end{tabular}



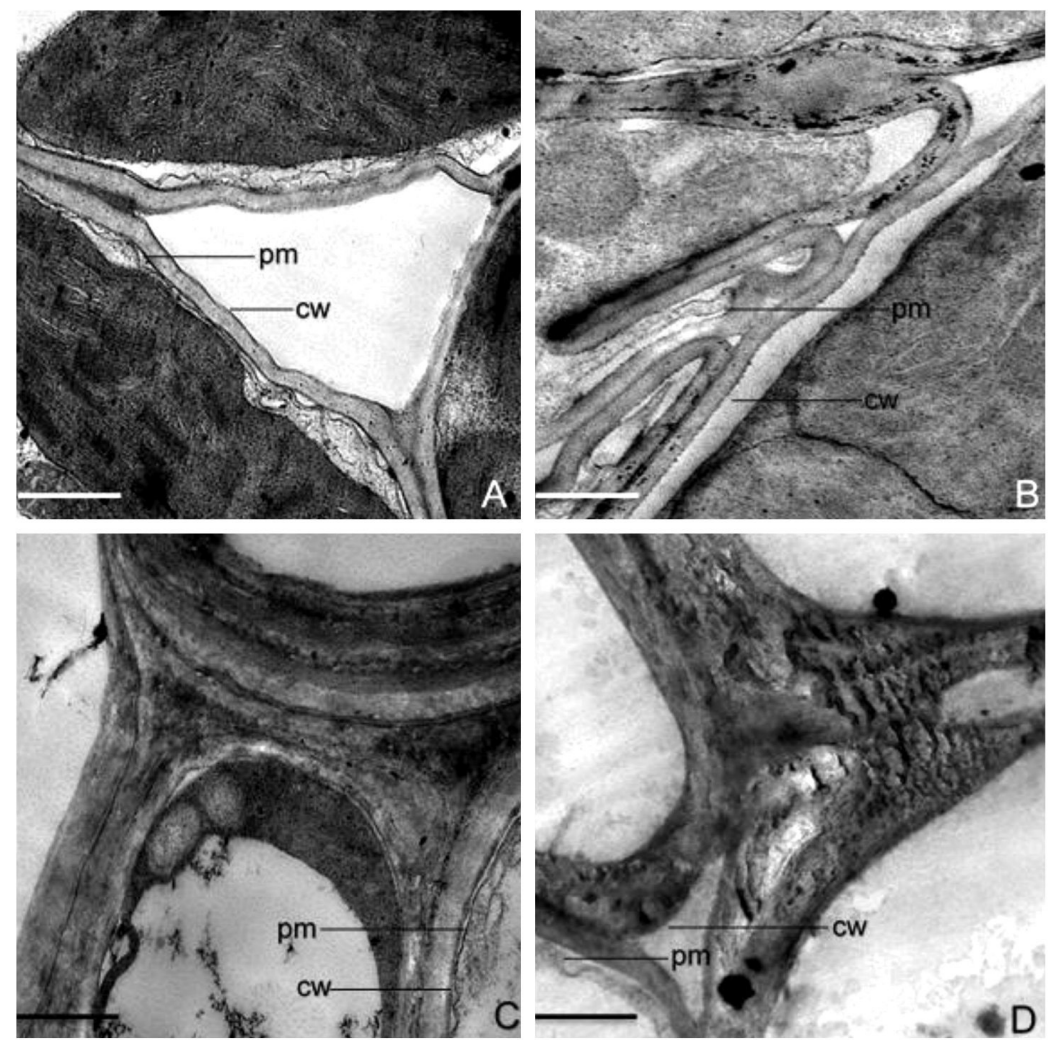

Fig. 4. Effect of heat stress and pretreatment with potassium silicate ( $\mathrm{Si}$ ) or silicon dioxide nanoparticle (SiNPs) on walls and membrane ultrastructure of mesophyll cells from wheat leaves. $A$ - control, normal temperature, $B$ - heat stress $\left(45^{\circ} \mathrm{C}\right.$ for $\left.4 \mathrm{~h}\right), C$ - Si pretreatment + heat stress, $D$ - SiNP pretreatment + heat stress; cw - cell wall, pm - plasma membrane, bars are $500 \mathrm{~nm}$.

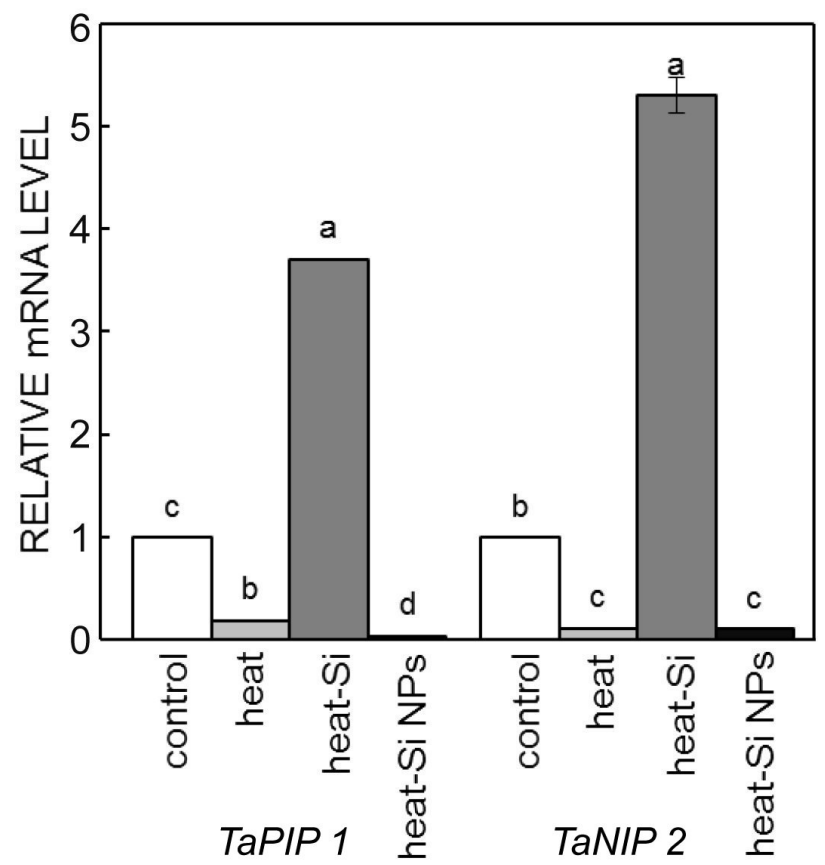

Fig. 5. Effect of heat stress and potassium silicate $(\mathrm{Si})$ or silicon dioxide nanoparticle (SiNP) pretreatment on Triticum aestivum plasma membrane intrinsic protein TaPIP1 and Triticum aestivum nodulin 26-like intrinsic protein TaNIP2 gene expressions in wheat seedling leaf tissue. Means \pm SEs, $n=3$, different letters indicate significant differences at $P \leq 0.05$.

\section{(Manivannan et al. 2016).}

The TEM results showed that heat stress induced changes in the shape and ultrastructure of chloroplast (Fig. 2B). The chloroplast grana were more sensitive than stroma and their disintegration might be attributed to the photooxidative damages resulted from ROS accumulation (Djanaguiraman et al. 2018). Meanwhile, grana decay was concomitant with an increase in the number of plastoglobuli occurred in chloroplast stroma suggesting the decomposition of thylakoid membrane lipids (Lutz et al. 2015). The distortion of the thylakoid membranes under heat stress leads to a significant inhibition of the photochemical reactions (Djanaguiraman et al. 2014). Assessment of the fluorescence parameters in terms of $\mathrm{F}_{\mathrm{V}} / \mathrm{F}_{\mathrm{M}}$ and $\mathrm{PI}_{\mathrm{abs}}$ reflects the photochemical efficiency of PS II and offers evidence about the functional and structural integrity of thylakoids (Kalaji et al. 2016). It was reported that the values of $\mathrm{F}_{\mathrm{V}} / \mathrm{F}_{\mathrm{M}}$ and $\mathrm{PI}_{\mathrm{abs}}$ altered under stress condition before the detection of the visible stress signs on the leaves (Christen et al. 2007). The current data showed that, heat stress induced a marked reduction in $\mathrm{PI}_{\mathrm{abs}}$ and $\mathrm{F}_{\mathrm{V}} / \mathrm{F}_{\mathrm{M}}$ values (Fig. $3 A, B$ ) concomitant with significant decreases in the Chl content in wheat leaves (Table 1). Indeed, the distortion of thylakoid membranes may also lead to chlorophyll loss as reported by Chuartzman et al. (2008). The pronounced reduction in $\mathrm{Chl} a$, Chl b, total Chl content, as well as $\mathrm{Chl} / \mathrm{Car}$ ratio may be due to either decreased biosynthesis of the chlorophyll and/or 
increased its degradation (Dutta et al. 2009). Moreover, the decrease in Chl $a$, Chl $b$, and total Chl content in response to heat stress had earlier been ascribed to photooxidation of chlorophyll (Guo et al. 2007). Likewise, the reduction in the $F_{V} / F_{M}$ values in stressed wheat leaves may resulted from the conformational changes and damages of the reaction center of photosystem (PS) II (Colom and Vazzana 2003) which causes imbalance between the generation and utilization of electrons, leading to photoinhibition (Li et al. 2016). Similar impacts of heat stress on the pigments associated with other photosynthetic performance has been reported by Yüzbaşioğlu et al. (2017) on maize and Djanaguiraman et al. (2018) on wheat. However, $\mathrm{PI}_{\mathrm{abs}}$ and $\mathrm{F}_{\mathrm{V}} / \mathrm{F}_{\mathrm{M}}$ were improved in the $\mathrm{Si}$ - or SiNPs treatment concomitant with the preservation of chloroplast ultrastructure (Fig. $2 C, D$ ) as well as the content of photosynthetic pigments (Table 1). Notably, $\mathrm{Si}$ was more effective than SiNPs in this regard. The effect of $\mathrm{Si}$ on the photosynthetic apparatus can be attributed to its positive impact on plant water status (Fig. $3 F$ ), as well as on the possible uptake and accumulation of both macro and micronutrients (Savić and Marjanović-Jeromela 2013). Also, Si can induce the synthesis of new pigments and help in the maintenance of previously existing Chl $a$ (Silva et al. 2012). Tuna et al. (2008) and Ma et al. (2016) obtained similar results on stressed wheat. Meanwhile the increasing $\mathrm{PI}_{\mathrm{abs}}$ value by $\mathrm{Si}$ treatment may be related to the increase in the density of the active reaction centers of PS II (Ghassemi-Golezani and Lotfi 2015). Also SiNPs are characterized by their high reactivity and thereby they can bound with PS II and so stabilize the photosynthetic activity under stress conditions (Noji et al. 2010).

The distortions of the plasma membrane and cell walls were detected by TEM in heat-stressed wheat leaves (Fig. 4B). Such effect is attributed to osmotic stress concomitant with thermal stress (Lima et al. 2013), as well as the alterations of membrane proteins and lipids induced by high temperature (Somerville and Browse 1991, Agarie et al. 1998). Meanwhile, Si or SiNPs treatments maintained the integrity of both cell walls and cell membranes (Fig. 4C,D). Such impact on the cell walls was resulted from the deposition of either $\mathrm{Si}$ or SiNPs at the interface of the plasma membrane with the cell wall and/ or in the intercellular spaces (Bauer et al. 2011, Sun et al. 2014, Asgari et al. 2018). In addition, SiNPs deposited in cytoplasm and in cell organelles such as the vacuoles (Sun et al. 2014). Both Si and SiNPs mitigated the adverse effects of heat stress, but with different intensities.

Interestingly, the observed increase in MDA content (Fig. 3C) was positively related to the abundance of plastoglobuli in the thylakoids of stressed leaves (Fig. 2B). Similar results have been obtained by Shah et al. (2013). The present investigation also showed that Si or SiNPs treatment reduced MDA content concomitant with increments in membrane stability index (Fig. 3C,E). Such result might resulted from the enhanced DPPH scavenging capacity (Fig. 3D). Similarly, the enhancement of the antioxidant defense systems in plants was reported by Kim et al. (2017), and Merwad et al. (2018) in different Si- treated plants. Furthermore, SiNPs stimulated the antioxidant system in stressed tomato and squash plants (Haghighi et al. 2012, Siddiqui et al. 2014).

Notably, maintenance of greater leaf water content under heat stress is one of the remarkable effects of $\mathrm{Si}$ and SiNPs (Fig. $3 F$ ) and maximum increase in RWC was displayed in Si-treated leaves. Such effect may be due to the greater deposition of Si compared to SiNPs in the leaf tissues (Fig. 4C,D), decreasing water loss and thus protecting plants from water desiccation induced by heat stress (Ma 2004, Coskun et al. 2019). Despite the role of Si or SiNPs in maintenance of water content, it is interesting to explore the role of $\mathrm{Si}$ or SiNPs in improving the water status in heat stressed plants via AQPs performance. The regulation of AQP coding genes expressions contributes in the stress adaptation mechanisms. However, their role in the improvement of plant tolerance against heat stress remains to be a challenge (Kapilan et al. 2018). The results of the current work showed a reduction in TaPIPI and TaNIP2 gene expressions in heat stressed wheat seedlings (Fig. 5). Meanwhile, Si treatment induced the overexpression of TaPIP1 and TaNIP2 (Fig. 5). Such increase in gene expression may be at the transcriptional level (Hu et al. 2012). Our finding is supported by those of Zhu et al. (2015) who reported that silicon increased the expression of members of the PIP2 subfamily resulting in an increase in water uptake. In fact, AQPs act as multifunctional channels that transport water and many small molecules such as silicon (Fox et al. 2017). Silicon compounds can be translocated by TaPIPS and TaNIPS transporters, however, the SiNPs, due to their small size, can diffuse through the cell walls (Asgari et al. 2018). The current data proved that unlike Si treatment, TaPIP1 and TaNIP2 genes expression in the SiNPs-treated stressed leaves was relatively unaffected (Fig. 5). The present observations assumed that, the flow of SiNPs is independent on the TaPIP1 and TaNIP2 transporters. Meanwhile, SiNPs improved thermotolerance via maintaining water status which achieved by the mechano-physical strategy only. Additional experimental work is needed to explore the molecular mechanism of Si and SiNPs in improving thermotolerance.

In conclusion, the current observations inferred that imposition of high temperature caused reduction in RWC, distortion in the cellular structures, decrease in photosynthetic system performance, and membrane damages. The results also illustrated that soaking of wheat grains in either Si or SiNPs solutions could ameliorate some heat stress induced injuries including decrease in RWC, ultrastructural changes of mesophyll cells, MSI index, parameters of chlorophyll fluorescence $\left(\mathrm{PI}_{\mathrm{abs}}, \mathrm{F}_{\mathrm{V}} / \mathrm{F}_{\mathrm{M}}\right)$, and MDA accumulation as well as they enhanced the DPPH scavenging activity. Notably, Si was more effective than SiNPs in alleviation of adverse effects of heat. Meanwhile, maintaining greater RWC in heat stressed wheat leaves is one of the remarkable effects of $\mathrm{Si}$ which was associated with the significant overexpression of TaPIP1 and TaNIP2 compared with the relatively unaffected ones in SiNPs-treated wheat leaves. Therefore, the data of current investigation added innovative knowledge for the improvement of thermotolerance and gave additional 
support to the proposed roles of Si or SiNPs in plant responses to heat stress.

\section{References}

Abdel Latef, A.A., Tran, L.S.P.: Impacts of priming with silicon on the growth and tolerance of maize plants to alkaline stress. - Front. Plant Sci. 7: 243, 2016.

Agarie, S., Hanaoka, N., Ueno, O., Miyazaki, A., Kubota, F., Agata, W., Kaufman, P.B.: Effects of silicon on tolerance to water deficit and heat stress in rice plants (Oryza sativa L.) monitored by electrolyte leakage. - Plant Prod. Sci. 1: 96-103, 1998.

Alsaeedia, A., El-Ramadyb, H., Alshaa, T., El-Garawanic, M., Elhawat, N., Al-Otaibi, A.: Exogenous nanosilica improves germination and growth of cucumber by maintaining $\mathrm{K}^{+} / \mathrm{Na}^{+}$ ratio under elevated $\mathrm{Na}^{+}$stress. - Plant Physiol. Biochem. 125: 164-171, 2018.

Alzahrani, Y., Kuşvuran, A., Alharby, H.F., Kuşvuran, S., Rady, M.M.: The defensive role of silicon in wheat against stress conditions induced by drought, salinity or cadmium. Ecotoxicol. Environ. Safety 154: 187-196, 2018.

Asgari, F., Majd, A., Jonoubi, P., Najafi, F.: Effects of silicon nanoparticles on molecular, chemical, structural and ultrastructural characteristics of oat (Avena sativa L.). - Plant Physiol. Biochem. 127: 152-160, 2018.

Bajwa, A.A., Chauhan, B.S. Adkins, S.: Morphological, physiological and biochemical responses of two Australian biotypes of Parthenium hysterophorus to different soil moisture regimes. - Environ. Sci. Pollut. Res. 24: 1618616194, 2017.

Bauer, P., Elbaum, R., Weiss, I.M.: Calcium and silicon mineralization in land plants: transport, structure and function. - Plant Sci. 180: 746-756, 2011.

Blum, A.: The effect of heat stress on wheat leaf and ear photosynthesis. - J. exp. Bot. 37: 111-118, 1986.

Chen, K., Arora, R.: Understanding the cellular mechanism of recovery from freeze-thaw injury in spinach: possible role of aquaporins, heat shock proteins, dehydrin and antioxidant system. - Physiol. Plant. 150: 374-387, 2014.

Christen, D., Schönmann, S., Jermini, M., Strasser, R.J., Défago, G.: Characterization and early detection of grapevine (Vitis vinifera) stress responses to esca disease by in situ chlorophyll fluorescence and comparison with drought stress. - Environ. exp. Bot. 60: 504-514, 2007.

Christou, A., Filippou, P., Manganaris, G.A., Fotopoulos, V.: Sodium hydrosulphide induces systemic thermotolerance to strawberry plants through transcriptional regulation of heat shock proteins and aquaporin. - BMC Plant Biol. 14: 42, 2014.

Chuartzman, S.G., Nevo, R., Shimoni, E., Charuvi, D., Kiss, V., Ohad, I., Reich, Z.: Thylakoid membrane remodeling during state transitions in Arabidopsis. - Plant Cell 20: 1029-1039, 2008.

Colom, M.R., Vazzana, C.: Photosynthesis and PSII functionality of drought-resistant and drought-sensitive weeping lovegrass plants. - Environ. exp. Bot. 49: 135-144, 2003.

Coskun, D., Deshmukh, R., Sonah, H., Menzies, J.G., Reynolds, O., Ma, J.F., Kronzucker, H.J., Bélanger, R.R.: The controversies of silicon's role in plant biology. - New Phytol. 221: 67-85, 2019.

Cossani, C.M., Reynolds, M.P.: Physiological traits for improving heat tolerance in wheat. - Plant Physiol. 160: 1710-1718, 2012.

Curtis, T., Halford, N.G.: Food security: the challenge of increasing wheat yield and the importance of not compromising food safety. - Ann. appl. Biol. 164: 354-372, 2014.

Dankov, K., Rashkov, G., Misra, A., Apostolova, E.L.: Temperature sensitivity of photosystem II in isolated thylakoid membranes from fluridone-treated pea leaves. - Turk. J.. Bot. 39: 420-428, 2015.

Djanaguiraman, M., Boyle, D.L., Welti, R., Jagadish, S.V.K., Prasad, P.V.V.: Decreased photosynthetic rate under high temperature in wheat is due to lipid desaturation, oxidation, acylation, and damage of organelles. - BMC Plant Biol. 18: $55,2018$.

Djanaguiraman, M., Prasad, P.V., Murugan, M., Perumal, R., Reddy, U.K.: Physiological differences among sorghum (Sorghum bicolor L. Moench) genotypes under high temperature stress. - Environ. exp. Bot. 100: 43-54, 2014.

Dutta, S., Mohanty, S., Tripathy, B. C.: Role of temperature stress on chloroplast biogenesis and protein import in pea. - Plant Physiol. 150: 1050-1061, 2009.

Fahad, S., Bajwa, A.A., Nazir, U., Anjum, S.A., Farooq, A., Zohaib, A., Sadia, S., W., Nasim, Adkins, S., Saud, S., Ihsan, M.Z., Alharby, H., Wu, C., Wang, D., Huang, J.: Crop production under drought and heat stress: plant responses and management options. - Front. Plant Sci. 8: 1147, 2017.

Fox, A.R., Maistriaux, L.C., Chaumont, F.: Toward understanding of the high number of plant aquaporin isoforms and multiple regulation mechanisms. - Plant Sci. 264: 179-187, 2017.

Ghassemi-Golezani, K., Lotfi, R.: The impact of salicylic acid and silicon on chlorophyll a fluorescence in mung bean under salt stress. - Russ. J. Plant Physiol. 62: 611-616, 2015.

Gong, H., Chen, K.: The regulatory role of silicon on water relations, photosynthetic gas exchange, and carboxylation activities of wheat leaves in field drought conditions. - Acta. Physiol. Plant. 34: 1589-1594, 2012.

Guo, Z., Huang, M., Lu, S., Yaqing, Z., Zhong, Q.: Differential response to paraquat induced oxidative stress in two rice cultivars on antioxidants and chlorophyll $a$ fluorescence. Acta Physiol. Plant. 29: 39-46, 2007.

Gupta, A.B. and Sankararamakrishnan, R.: Genome-wide analysis of major intrinsic proteins in the tree plant Populus trichocarpa: characterization of XIP subfamily of aquaporins from evolutionary perspective. - BMC Plant Biol. 9: 134, 2009.

Haghighi, M., Afifipour, Z., Mozafarian, M.: The effect of N-Si on tomato seed germination under salinity levels. - J. Biol. environ. Sci. 6: 87-90, 2012.

Hatano, T., Kagav, H., Yasuhar, T., Okuda, T.: Two new flavonoids and other constituents in licorice root: their relative astringency and radical scavenging affects. - Chem. pharm. Bull. 36: 1090-2097, 1988.

Heath, R.L., Packer, L.: Photoperoxidation in isolated chloroplasts. I. kinetics and stoichiometry of fatty acid peroxidation. - Arch. Biochem. Biophys. 125: 189-198, 1968.

Hossain, Z., Mustafa, G., Komatsu, S.: Plant responses to nanoparticle stress. - Int. J. mol. Sci. 16: 26644-26653, 2015.

Hu, W., Yuan, Q., Wang, Y., Cai, R., Deng, X., Wang, J., Zhou, S., Chen, M., Chen, L., Huang, C., Ma, Z.: Overexpression of a wheat aquaporin gene, $T a A Q P 8$, enhances salt stress tolerance in transgenic tobacco. - Plant Cell Physiol. 53: 2127-2141, 2012.

Hussain, A., Rizwan, M., Ali, Q., Ali, S.: Seed priming with silicon nanoparticles improved the biomass and yield while reduced the oxidative stress and cadmium concentration in wheat grains. - Environ. Sci. Pollut. Res. 26: 7579-7588, 2019.

Hussain, S.S., Iqbal, M.T., Arif, M.A., Amjad, M.: Beyond osmolytes and transcription factors: drought tolerance in 
plants via protective proteins and aquaporins. - Biol. Plant. 55: 401-413, 2011.

Ihsan, M.Z., Daur, I., Alghabari, F., Alzamanan, S., Rizwan, S., Ahmad, M.: Heat stress and plant development: role of sulphur metabolites and management strategies. - Acta agr. scand. 69: 332-342, 2019.

Ionenko I.F., Anisimov, A.V., Dautova, N.R.: Effect of temperature on water transport through aquaporins. - Biol. Plant. 54: 488-494, 2010.

Kalaji, H.M., Jajoo, A., Oukarroum, A., Brestic, M., Zivcak, M., Samborska, I.A., Cetner, M.D., Łukasik, I., Goltsev, V., Ladle, R.J.: Chlorophyll a fluorescence as a tool to monitor physiological status of plants under abiotic stress conditions. - Acta Physiol. Plant. 38: 102, 2016.

Kapilan, R., Vaziri, M., Zwiazek, J.J.: Regulation of aquaporins in plants under stress. - Biol. Res. 51: 1-4, 2018.

Khan, S., Thomas B.R., De la Mata, R., Randall, M.J., Zhang, W., Zwiazek, J.J.: Variation in aquaporin and physiological responses among Pinus contorta families under different moisture conditions. - Plants 8: 13-??, 2019.

Kim, Y.H., Khan, A.L., Waqas, M., Lee, I.J.: Silicon regulates antioxidant activities of crop plants under abiotic-induced oxidative stress: a review. - Front. Plant Sci. 8: 510-??, 2017.

Lang-Mladek, C., Popova, O., Kiok, K., Berlinger, M., Rakic, B., Aufsatz, W., Jonak, C., Hauser, M. T., Luschnig, C.: Transgenerational inheritance and resetting of stress-induced loss of epigenetic gene silencing in Arabidopsis. - Mol. Plant 3: 594-602, 2010.

Li, H., Ahammed, G.J., Zhou, G., Xia, X., Zhou, J., Shi, K., Yu, J., Zhou, Y.: Unraveling main limiting sites of photosynthesis under below-and above-ground heat stress in cucumber and the alleviatory role of luffa rootstock. - Front. Plant Sci. 7: 746, 2016.

Lima, R.B., Dos Santos, T.B., Vieira, L.G.E., Ferrarese, M.D.L.L., Ferrarese-Filho, O., Donatti, L., Boeger, M.R.T., De Oliveira Petkowicz, C.L.: Heat stress causes alterations in the cell-wall polymers and anatomy of coffee leaves (Coffea arabica L.). - Carbohyd. Polymers 93: 135-143, 2013.

Liu, D., Zhang, D., Liu, G., Hussain, S., Teng, Y.: Influence of heat stress on leaf ultrastructure, photosynthetic performance and ascorbate peroxidase gene expression of two pear cultivars (Pyrus pyrifolia). - J. Zhejiang Univ. Section B 14: 1070-1083, 2013.

Liu, R., Lal, R.: Potentials of engineered nanoparticles as fertilizers for increasing agronomic productions. - Sci. total Environ. 514: 131-139, 2015

Livak, K.J., Schmittgen, T.D.: Analysis of relative gene expression data using real-time quantitative PCR and the (2$\Delta \Delta \mathrm{Ct})$ method. - Methods 25: 402-408, 2001.

Lutz, C., Di-Piazza, L., Fredersdorf, J., Bischof, K.: The effect of ultra-violet radiation on cellular ultrastructure and photosystem II quantum yield of Alaria esculenta (L.) Greville from Spitsbergen (Norway). - Polar Biol. 39: 19571966, 2015.

Ma, D., Sun, D., Wang, C., Qin, H., Ding, H., Li, Y., Guo, T.: Silicon application alleviates drought stress in wheat through transcriptional regulation of multiple antioxidant defense pathways. - J. Plant Growth Regul. 35: 1-10, 2016.

Ma, J.F.: Role of silicon in enhancing the resistance of plants to biotic and abiotic stresses. - J. Soil Sci. Plant Nutr. 50: 11-18, 2004.

Manivannan, A., Soundararajan, P., Muneer, S., Ko, C.H., Jeong, B.R.: Silicon mitigates salinity stress by regulating the physiology, antioxidant enzyme activities, and protein expression in Capsicum annuum 'Bugwang'. - Biomed. Res. Int. 3076357, 2016.
Maurel, C., Boursiac, Y., Luu, D.T., Santoni, V., Shahzad, Z., Verdoucq, L.: Aquaporins in plants. - Physiol. Rev. 95: 1321$1358,2015$.

Merwad, A., Desoky, E.S., Rady, M.M.: Response of water deficit stressed Vigna unguiculata performances to silicon, proline or methionine foliar application. - Sci. Hort. 228: 132-144, 2018.

Metzner, H., Rau, H., Senger, H.: [Studies on the synchronizability of individual pigment deficiency mutants of Chlorella.] Planta 65: 186-194, 1965. [In Ger.]

Nair, P.M.G., Chung, I.M.: Physiological and molecular level studies on the toxicity of silver nanoparticles in germinating seedlings of mung bean (Vigna radiata L.). - Acta Physiol. Plant. 37: 1719, 2015.

Noji, T., Kamidaki, C., Kawakami, K., Shen, J.R., Kajino, T., Fukushima, Y., Sekitoh, T., Itoh, S.: Photosynthetic oxygen evolution in mesoporous silica material: adsorption of photosystem II reaction center complex into $23 \mathrm{~nm}$ nanopores in SBA. - Langmuir 27: 705-713, 2010.

Park, W., Scheffler, B.E., Bauer, P.J., Campbell, B.T.: Identification of the family of aquaporin genes and their expression in upland cotton (Gossypium hirsutum L.). - BMC Plant Biol. 10: 142, 2010.

Pecinka, A., Dinh, H.Q., Baubec, T., Rosa, M., Lettner, N., Scheid, O.M.: Epigenetic regulation of repetitive elements is attenuated by prolonged heat stress in Arabidopsis. - Plant Cell 22: 3118-3129, 2010.

Pieczynski, M., Marczewski, W., Hennig, J., Dolata, J., Bielewicz, D., Piontek, P., Wyrzykowska, A., Krusiewicz, D., Strzelczyk-Zyta, D., Konopka-Postupolska, D., Krzeslowska, M., Jarmolowski, A., Szweykowska-Kulinska, Z.: Downregulation of CBP80 gene expression as a strategy to engineer a drought-tolerant potato. - Plant Biotechnol. J. 11: 459-469, 2013.

Rios, J.J., Martínez-Ballesta, M.C., Ruiz, J.M., Blasco, B., Carvajal, M.: Silicon-mediated improvement in plant salinity tolerance: the role of aquaporins. - Front. Plant Sci. 8: 948, 2017.

Sairam, R.K., Rao, K.V., Srivastava, G.C.: Differential response of wheat genotypes to long term salinity stress in relation to oxidative stress, antioxidant activity and osmolyte concentration. - Plant Sci. 163: 1037-1046, 2002.

Santos, A.P., Ferreira, L., Maroco, J., Oliveira, M.M.: Abiotic stress and induced DNA hypomethylation cause interphase chromatin structural changes in rice rDNA loci. - Cytogenet. Genome Res. 132: 297-303, 2011.

Savić, J., Marjanović-Jeromela, A.: Effect of silicon on sunflower growth and nutrient accumulation under low boron supply. Helia 36: 61-68, 2013.

Shah, K., Singh, P., Nahakpam, S.: Effect of cadmium uptake and heat stress on root ultrastructure, membrane damage and antioxidative response in rice seedlings. - J. Plant Biochem. Biotechnol. 22: 103-112, 2013.

Siddiqui, M.H., Al-Whaibi, M.H., Faisal, M., Al Sahli, A.A.: Nano-silicon dioxide mitigates the adverse effects of salt stress on Cucurbita pepo L. - Environ. Toxicol. Chem. 33: 2429-2437, 2014.

Silva, O.N., Lobato, A.K.S., Ávila, F.W., Costa, R.C.L., Neto, C.O., Santos Filho, B.G., Martins Filho, A.P., Lemos, R.P., Pinho, J.M., Medeiros, M.B.C.L., Cardoso, M.S.: Siliconinduced increase in chlorophyll is modulated by the leaf water potential in two water-deficient tomato cultivars. - Plant Soil Environ. 58: 481-486, 2012.

Somerville, C. Browse, J.: Plant lipids: metabolism, mutants and membranes. - Science 252: 80-87, 1991.

Spurr, A.R.: A low-viscosity epoxy resin embedding medium for electron microscopy. - J. Ultramicros. Res. 26: 31-43, 1969. 
Stirbet, A., Govindjee: On the relation between the Kautsky effect (chlorophyll $a$ fluorescence induction) and photosystem II: basics and applications. - J. Photochem. Photobiol. B: Biol. 104: 236-257, 2011.

Strasser, R.J., Tsimilli-Michael, M., Srivastava, A.: Analysis of the chlorophyll $a$ fluorescence transient. - In: Papageorgiou, G.C., Govindjee, (ed.): Chlorophyll $a$ Fluorescence. Advances in Photosynthesis and Respiration. Vol. 19. Pp. 321-362. Springer, Dordrecht 2004.

Sun, D., Hussain, H.I., Yi, Z., Siegele, R., Cresswell, T., Kong, L., Cahill, D.M.: Uptake and cellular distribution, in four plant species, of fluorescently labeled mesoporous silica nanoparticles. - Plant Cell Rep. 33: 1389-1402, 2014.

Tan, W., Meng, Q.W., Brestic, M., Olsovska, K., Yang, X.: Photosynthesis is improved by exogenous calcium in heatstressed tobacco plants. - J. Plant Physiol. 168: 2063-2071, 2011.

Tuna, A.L., Kaya, C., Higgs, D., Murillo-Amador, B., Aydemir, S., Girgin, A.R.: Silicon improves salinity tolerance in wheat plants. - Environ exp. Bot. 62: 10-16, 2008

Wang, Q., Chen J., He, N.Y., Guo, F.: Metabolic reprogramming in chloroplasts under heat stress in plants. - Int. J. mol. Sci. 19: 849, 2018.

Wang, X., Cai, J., Liu, F., Dai, T., Cao, W., Wollenweber, B., Jiang, D.: Multiple heat priming enhances thermo-tolerance to a later high temperature stress via improving subcellular antioxidant activities in wheat seedlings. - Plant Physiol. Biochem. 74: 185-192, 2014.

Wang, Y., Zhang, B., Jiang, D., Chen, G.: Silicon improves photosynthetic performance by optimizing thylakoid membrane protein components in rice under drought stress. Environ. exp. Bot. 158: 117-124, $2019 b$.

Yaneff, A., Sigaut, L., Gomez, N., Fandino, C.A., Alleva, K., Pietrasanta, L.I., Amodeo, G.L.: B serine of a plasma membrane aquaporin type PIP2 but not PIP1 plays a key role in $\mathrm{pH}$ sensing. - Biochim. biophys. Acta 1858: 2778-2787, 2016.

Yavaş, İ., Aydın, Ü.N.A.Y.: The Role of silicon under biotic and abiotic stress conditions. - Türkiye Tarımsal Araştırmalar Dergisi 4: 204-209, 2017.

Yüzbaşioğlu, E., Dalyan, E., Akpinar, I.: Changes in photosynthetic pigments, anthocyanin content and antioxidant enzyme activities of maize (Zea mays L.) seedlings under high temperature stress conditions. - Irak. Univ. J. nat. Sci. 18: 97-104, 2017.

Zhu, Y.X., Xu, X.B., Hu, Y.H., Han, W.H., Yin, J.L., Li, H.L., Gong, H.J.: Silicon improves salt tolerance by increasing root water uptake in Cucumis sativus L. - Plant Cell Rep. 34: 16291646, 2015.

Zwiazek, J.J., Xu, H., Tan, X., Navarro-Rodenas, A., Morte, A.: Significance of oxygen transport through aquaporins. - Sci. Rep. 7: 40411, 2017. 